\title{
Evidence for somatic translocation during potato dihaploid induction
}

\author{
M. J. WILKINSON*, S. T. BENNETT† \\ K. HARDING \& M. D. BENNETT† \\ Scottish Crop Research Institute, Invergowrie, Dundee DD2 5DA and †Jodrell Laboratory, Royal Botanic Gardens, Kew, \\ Richmond TW9 $3 A B$, U.K.
}

\begin{abstract}
Potato dihaploid PDH55 (Solanum tuberosum) is exclusively euploid $(2 n=24)$ but apparently contains and expresses DNA from dihaploid inducer IVP48 ( $S$. phureja). Genomic in situ hybridization (GISH) suggested IVP48 DNA incorporated stably into PDH55 by somatic translocation. This finding has two important implications. Firstly, the long-held implicit assumption that euploid dihaploids produced by dihaploid inducers are pure $S$. tuberosum seems incorrect. This may complicate meiotic, genetical and molecular studies involving potato dihaploids. Secondly, if such translocations are not rare, the phenomenon may offer a novel way to introduce useful traits directly from wild dihaploid-inducing species into $S$. tuberosum.
\end{abstract}

Keywords: dihaploid induction, in situ hybridization, Solanum tuberosum, somatic interchange.

\section{Introduction}

Dihaploids $(2 n=24)$ play a critical role in the genetic improvement of Solanum tuberosum $(2 n=48)$. Their main value lies in simplifying the complex genetics of the cultivated crop. This utility is based on the assumption that dihaploids are genetically pure $S$. tuberosum and so can be regarded as gametic samples of their tetraploid parents. The belief that dihaploids are formed by parthenogenesis (Hermsen \& Verdenius, 1973; Rowe, 1974) led to their widespread use in tissue culture, cytology and genetical studies of the potato (Ross, 1986; Visser et al., 1989; Peloquin et al., 1990; Williams et al., 1990) including the construction of linkage maps (e.g. Bonierbale et al., 1988; Gebhardt et al., 1993). Breeding strategies based on the selection and fusion of agronomically desirable dihaploids were developed (Chase, 1963; Sosa-Chavez \& Hernandez de Sosa, 1971; Wenzel et al., 1979) and have been adopted by many research groups worldwide.

Nearly all dihaploids are made by pollinating tetraploid potatoes using clones of $S$. phureja known as 'dihaploid inducers'. Many produce dihaploid plants that contain additional chromosomes in some cells (Clulow et al., 1991). Dihaploids with extra chromo-

\footnotetext{
*Correspondence.

$\Varangle$ Present address: Nuffield Department of Surgery, John Radcliffe Hospital, Oxford OX3 9LU, U.K.
}

somes usually also contain DNA markers and/or isozyme markers specific to the dihaploid inducer (Clulow et al., 1991, 1993). Clearly, such dihaploids cannot be regarded as gametic samples and, as they are chimeric for chromosome number, their value for genetical studies is limited. Here we examine an entirely euploid dihaploid $(2 n=24)$ and attempt to establish if it can be regarded as a gametic representative of $S$. tuberosum.

\section{Materials and methods}

\section{PCR analysis}

Genomic DNA was extracted from $1 \mathrm{~g}$ of fresh material using the CTAB method of Doyle \& Doyle (1987). PCR analyses were performed on DNA from cv. Pentland Crown, PDH55 and IVP48 using random primers (from kits A-D, Operon Technologies) according to the procedure described by Waugh et al. (1992).

\section{Southern analysis of PCR ge/s}

PCR gels were denatured, neutralized and Southern blotted onto a nylon membrane (Tropilon, Tropix) as described by Sambrook et al. (1989).

Preparation of probe PCR products derived from IVP48 were fractionated in a 1.2 per cent low melting 
point agarose (Sigma) gel in TBE buffer at $40 \mathrm{~V}$ for $1 \mathrm{~h}$. The discriminatory fragment $(850 \mathrm{bp})$ was removed as a thin gel slice and incubated at $100^{\circ} \mathrm{C}$ for $3 \mathrm{~min}$ to melt the agarose and denature the DNA. The sample was held at $37^{\circ} \mathrm{C}$ and labelled with biotin-7dATP using the random priming reaction according to the manufacturers' instructions (BoehringerMannheim). DNA hybridization and detection of chemiluminescent DNA sequences were performed according to the method of Harding (1992).

\section{Esterase activity}

Fresh leaf material $(0.25 \mathrm{~g})$ was ground in $200 \mathrm{~mL}$ of $25 \mathrm{mM} \mathrm{Na}_{2} \mathrm{HPO}_{4}, 10 \mathrm{~mm}$ DTT, 10 per cent w/v sucrose, $\mathrm{pH} 7.4$, centrifuged at $12000 \mathrm{~g}$ for $4 \mathrm{~min}$ and the supernatant removed. A $\mathrm{pH} 4-6.5$ isoelectric focusing gel ( 4.5 per cent $\mathrm{w} / \mathrm{v}$ acrylamide, 14 per cent glycerol, 5 per cent ampholyte) was prefocused at 0.5 $\mathrm{kV}, 22 \mathrm{~mA}, 40 \mathrm{~W}$ for $0.5(\mathrm{kV}) \mathrm{h}$ with electrode strips soaked in $1 \mathrm{M} \mathrm{H}_{3} \mathrm{PO}_{4}$ (anode) and $1 \mathrm{M} \mathrm{NaOH}$ (cathode). Then $15 \mu \mathrm{L}$ of supernatant from each sample was loaded onto the gel and separated at $2 \mathrm{kV}$, $22 \mathrm{~mA}, 40 \mathrm{~W}$ for $4.5(\mathrm{kV}) \mathrm{h}$. Gels were stained for $\alpha$ esterase activity according to Clulow et al. (1993).

\section{Preparation of chromosome spreads}

Chromosome counts of IVP48, cv. Pentland Crown and PDH55 were made using the method given by Clulow et al. (1991). Roots to be used for in situ hybridization were pretreated in iced water for $24 \mathrm{~h}$ and fixed in 3:1 ethanol:glacial acetic acid. Root tips were softened enzymically (Pijnacker et al., 1987), smeared onto a slide in a drop of 45 per cent acetic acid and viewed under phase contrast microscopy. Slides containing good spreads were placed on dry ice, the cover slips removed and air-dried overnight in an oven at $45^{\circ} \mathrm{C}$. Slides were stored for up to a week in a desiccator at $4^{\circ} \mathrm{C}$.

\section{In situ hybridization}

Genomic DNA was mechanically sheared by repeatedly passing through a $1 \mathrm{~mL}$ syringe fitted with a micro-gauge needle to form fragments largely in the range $10-12 \mathrm{~kb}$, as assessed on a 1.2 per cent agarose gel. For use as a probe, 2-3 $\mu$ g of IVP48 DNA were labelled with biotin-14-dATP by nick translation according to the manufacturers' instructions (Gibco BRL BioNick labeling system). Biotinylated, singlestranded genomic DNA of IVP48 was hybridized to denatured chromosomal DNA of either IVP48, cv. Pentland Crown, or PDH55 as described by Bennett et al. (1992). Genomic DNA of cv. Pentland Crown, autoclaved to give 100-250 bp fragments, was added to the hybridization mixture $(\times 20$ blocking DNA) to increase specificity of the IVP48 probe (AnamthawatJonsson et al., 1990). The conditions used allow only DNAs with over 80 per cent sequence homology to form hybrids, assuming parameters affecting nucleic acid hybridization in solution can be applied to chromosomal DNA in situ (Meinkoth \& Wahl, 1984).

\section{Results and discussion}

Clone PDH55 was made in 1972 by crossing $S$. tuberosum cv. Pentland Crown $(2 n=48)$ with pollen from the $S$. phureja 'dihaploid inducer' IVP48 $(2 n=24)$. In 1992, plants derived from seven tubers of PDH55 were exclusively euploid $(2 n=24 ; 102$ cells examined). No variation was observed in the chromosome number of the parental genotypes. Of 24 RAPD primers found to discriminate between the parents, one (CATCCGTGCT) revealed an IVP48-specific marker in PDH55 (Fig. 1a). Southern analysis confirmed that bands in PDH55 and IVP48 were homologous (Fig. 1b). Waugh et al. (1992) produced similar evidence suggesting the presence of IVP48 DNA in PDH55 using the primer (GCTCGTCAAC). Moreoever, leaf proteins of PDH55 stained for $\alpha$-esterase activity included IVP48-specific isoforms (Fig. 1c). These data suggest that $S$. phureja DNA is present and expressed in PDH55.

Distribution of IVP48 DNA was assessed using GISH. Cytological preparations of cv. Pentland Crown, IVP48 and PDH55 were probed with biotinylated IVP48 DNA. Signal was detected over all chromosomes in IVP48 (Fig. 2a) and was either absent or present as numerous small dots in cv. Pentland Crown (data not shown). In PDH55, however, signal was present as large segments on three chromosomes (Fig. 2b).

The probe's ability to detect IVP48 DNA over the entire genome was demonstrated by the presence of signal over all chromosomes in IVP48 preparations. Thus, its failure to highlight whole chromosomes in PDH55 is not attributable to an inability to bind. This was further supported by the consistent number and location of segments observed in all well-spread preparations of PDH55. Clearly, IVP48 DNA has not incorporated into PDH55 as entire chromosomes.

In cells of PDH55, a strong signal was consistently observed on a distal segment of one chromosome and a lesser interstitial segment of a second. A smaller area of signal was seen on an interstitial region of a third chromosome. In most squashes, these three chromosomes were noticeably larger than others in the cell 


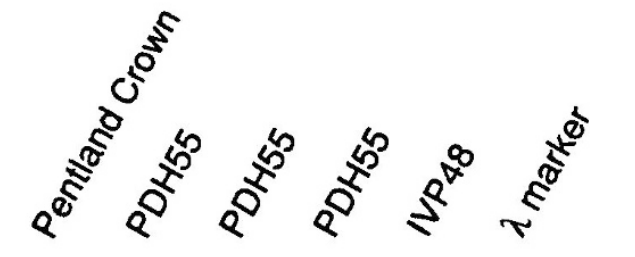

(a)

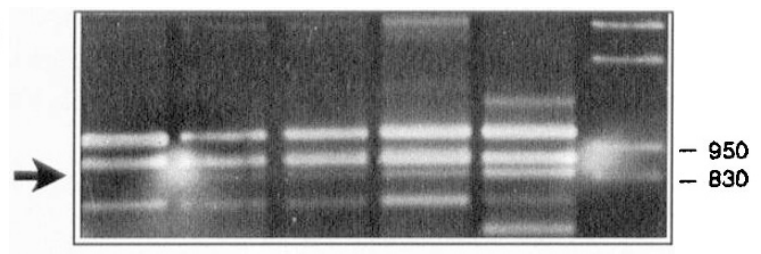

(b)
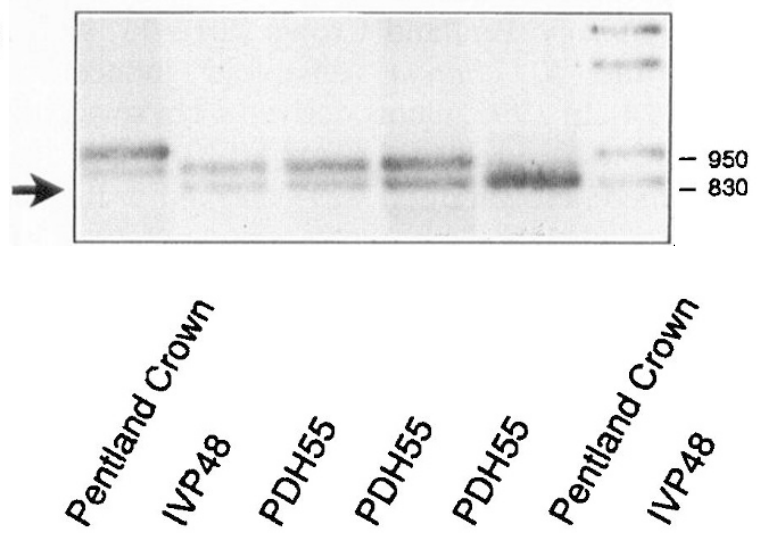

(c)

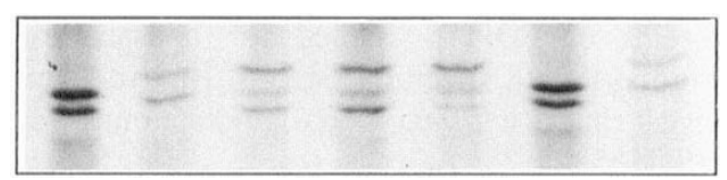

Fig. 1 Presence and expression of DNA from inducer IVP48 in potato dihaploid PDH55. (a) PCR analyses of cv. Pentland Crown, PDH55 and IVP48 using the random primer (CATCCGTGCT). (b) Southern analysis of the PCR gel, where the 850 bp IVP48-specific marker (arrowed) was recovered, biotin-labelled, hybridized and detected by chemiluminescence. The specific marker from IVP48 hybridized to comigrating bands from PDH55. (c) Leaf protein extracts from cv. Pentland Crown, PDH55 and IVP48 stained for $\alpha$-esterase activity. IVP48-specific isoforms are visible in each sample of PDH55.

(Fig. 2b, c). Cells of cv. Pentland Crown lacked signal or occasionally (less than 5 per cent of cells examined) had small spots of signal quite unlike the large segments observed in PDH55. It seems improbable from this observation that chromosome segments of conserved sequence homology could account for the large areas of signal detected in PDH55. Rather, it infers that these regions represent DNA from IVP48. These results suggest, therefore, that $S$. phureja DNA is present and expressed in PDH55, and is located on three $S$. tuberosum chromosomes. If so, translocation of $S$. phureja DNA to these sites must have occurred (a)

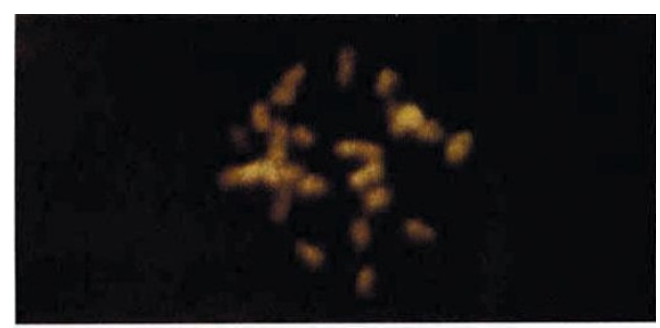

(b)

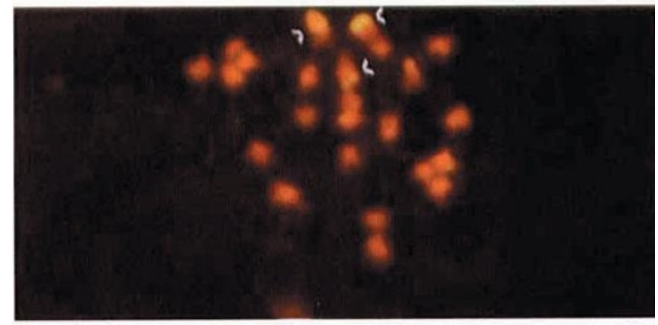

(c)

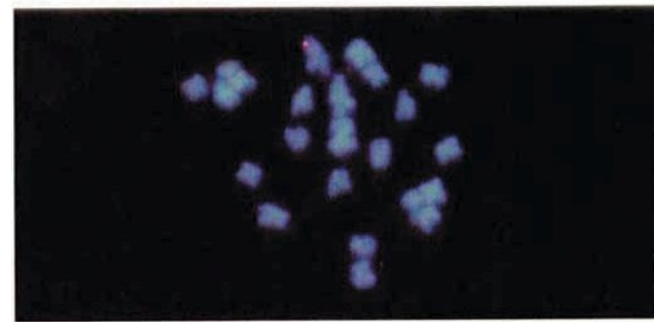

(d)
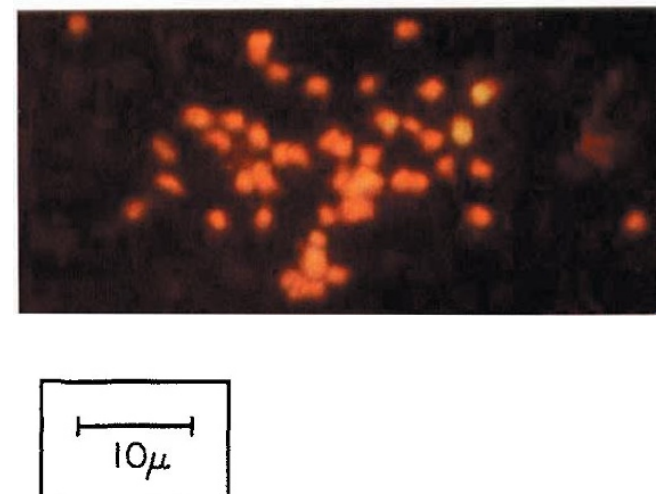

Fig. 2 Distribution of IVP48 DNA revealed by genomic in situ hybridization (GISH). (a) Cytological preparation from IVP48 roots probed with biotinylated IVP48 DNA and $\times 20$ concentration of autoclaved unlabelled DNA from cv. Pentland Crown showing signal on all chromosomes. (b) GISH on a PDH55 cell using the same probe mixture. Partial hybridization is visible on three chromosomes (arrowed). (c) The same PDH55 cell stained with 4',6-diamidino2-phenylindole (DAPI) and viewed under UV illumination. (d) Cell of a tetraploid regenerant of PDH55 showing signal on segments of six chromosomes.

somatically as the parental genomes united only after fertilization and thereafter PDH55 has been maintained clonally. S. tuberosum chromosomes lacking signal all appeared to be morphologically normal, per- 
haps suggesting that any translocation was exclusively from $S$. phureja to $S$. tuberosum.

No variation was seen for IVP48-specific $\alpha$-esterase or RAPD bands (Fig. 1), or in GISH patterns between PDH55 plants used in this study. Shoots produced from leaf-disc calli were used to investigate intercellular differences within PDH55. IVP48-specific RAPD bands in four regenerants did not differ from PDH55. Furthermore, GISH patterns in the one regenerant tested were indistinguishable from the original dihaploid. Thus, there was no evidence of cell-to-cell variation and the translocated DNA appeared to be stable and invariant.

The exact origin of any translocation is unknown but there are circumstantial grounds for supposing these examples occurred early in the development of PDH55. Dihaploid seeds are distinguished from IVP48 $\times S$. tuberosum hybrids by the absence of a phenotypic marker gene (Hermsen \& Verdenius, 1973) and, at the seedling stage, by ploidy level. This suggests that inducer chromosomes were present only early in development of PDH55. Translocations presumably occurred at that time because they would require the presence of inducer DNA. Early translocations would be consistent also with the invariability between PDH55 plants described above.

Somatic translocation has been induced in many plant species by chemical mutagenesis and ionizing irradiation (e.g. Heiner et al., 1960; Hagberg et al., 1975), and has played an important role in the genetics and breeding of several crop species (Lal \& Srinivasachar, 1979). GISH is a powerful tool for detecting translocations and has been used to demonstrate exchanges between ancestral genomes of Nicotiana tabacum (Kenton et al., 1993) and to examine Xirradiation-induced translocations between wheat $(T r i-$ ticum aestivum L.) and rye (Secale cereale L.) chromosomes of an addition line (Mukai et al., 1993). However, many recent reports on interspecific translocation in plants have been made using material grown in tissue culture. Interspecific translocations were reported in three somatic hybrids between Nicotiana plumbaginifolia and $N$. sylvestris (Parokonny et al., 1992) and in a somatic hybrid between Petunia parodii and $P$. parviflora (White \& Rees, 1985). Translocations involving chromosomes of $S$. tuberosum and/or $S$. phureja have also been reported. De Vries et al. (1987) detected inter- and intrageneric translocations in somatic hybrids between $N$. plumbaginifolia and monohaploid $S$. tuberosum. In another study, Ooms et al. (1985) examined 42 transformed regenerants of $S$. tuberosum cv. Desiree and found two hypotetraploids $(2 n=47)$ with structural rearrangements to chromosomes which they suggested probably arose by trans- locations. Similarly, Pijnacker et al. (1987) reported that somatic hybrids between $S$. phureja and dihaploid $S$. tuberosum possessed structural rearrangements to chromosomes attributed to asymmetrical reciprocal translocations. Spontaneous translocations between chromosomes 3 and 12 have also been observed in $S$. phureja plants grown outside tissue culture (Wagenvoort, 1988). Together, these reports suggest that translocations involving chromosomes of $S$. tuberosum and $S$. phureja may not be rare. However, it would also be premature to infer from this that translocations during dihaploid induction are commonplace.

The occurrence of translocation during dihaploid induction would mean that both euploid and aneusomatic dihaploids can contain inducer DNA. The importance of this observation to the many genetical studies that use dihaploids is dependent upon: (i) the frequency of translocation, (ii) the relationship (if any) between translocated DNA and recipient chromosome, and (iii) whether the transferred segments are stable. However, that it may occur at all has relevance to all such work. The occasional presence of alien DNA segments would complicate segregation analyses of crosses involving dihaploid plants and may affect meiotic pairing in potato dihaploids as well as in hybrids, tetraploids and monoploids derived from them.

Induction crosses frequently produce tetraploid offspring, some with the $S$. tuberosum phenotype. Close examination of these individuals usually reveals some dihaploid cells $(2 n=24)$, indicating an origin from somatically doubled dihaploid embryos (M. J. Wilkinson, unpublished data). Theoretically, translocated inducer DNA present in undoubled dihaploid embryos could be retained in such tetraploids, if the segments remained stable during somatic chromosome duplication. The retention of inducer DNA would represent direct introgression from the inducer species into tetraploid $S$. tuberosum without forming intermediate triploid or tetraploid hyrids. One of 12 regenerants of PDH55 found to have somatically doubled while in culture was used to test the stability of translocated segments during somatic chromosome duplication. Cells were probed with IVP48 DNA and found to possess six highlighted segments closely resembling those detected in PDH55 (Fig. 2d). This result suggests that IVP48 DNA can be stable during chromosome duplication and may be replicated along with the $S$. tuberosum DNA. Whether such cryptic introgression has occurred naturally during potato evolution is open to speculation. Although several wild and cultivated Solanum species have been shown to be capable of dihaploid induction in both $S$. tuberosum 
(Bukai, 1968; Budin, 1969; Montelongo-Escobedo \& Rowe, 1969) and S. stoloniferum (Marks, 1955), it needs to be demonstrated that these induction events also can be associated with somatic translocation.

Only a few $S$. phureja inducers are used to produce potato dihaploids. These clones all contain marker genes that enable easy selection of dihaploid seeds but none has been reported to contain agronomically desirable traits. However, some $S$. phureja individuals have resistances to commercially important diseases (Hawkes, 1990), as do several other species capable of dihaploid induction. Thus, provided translocation is not rare during dihaploid induction, it may be exploitable in potato breeding and genetics. Successful transfer of DNA containing useful traits would depend on several factors but particularly on whether the exchanged segments represent random portions of the inducers' genome.

\section{References}

ANAMTHAWAT-JONSSON, K., SCHWARZACHER, T., LEITCH, A. R., BENNETT, M. D. AND HESLOP-HARRISON, J. S. 1990. Discrimination between closely related Triticeae species using genomic DNA as a probe. Theor. Appl. Genet., 79, 721-728.

BENNETT, S. T., KENTON, A. Y. AND BENNETT, M. D. 1992. Genomic in situ hybridization reveals the allopolyploid nature of Milium montianum (Gramineae). Chromosoma, 101, 420-424.

BONIERBALE, M. W., PlAisted, R. L. AND TANKSLEY, S. T. 1988. RFLP maps based on a common set of clones reveal modes of chromosome evolution in potato and tomato. Genetics, 120, 1095-1103.

BUdiN, K. z. 1969. Obtaining potato dihaploids. Genetika, 5, 42-50.

BUKAI, J. 1968. Production of dihaploid forms of Solanum tuberosum. Rep. All-Un. Lenin Acad. Agric. Sci., 7, 14-17.

CHASE, S. E. 1963. Analytical breeding of Solanum tuberosum: a scheme utilizing parthenotes and other diploid stocks. Can. J. Genet. Cytol., 5, 359-363.

ClUlow, S. A., WLLKINSON, M. J. AND BURCH, L. R. 1993. Solanum phureja genes are expressed in the leaves and tubers of aneusomatic potato dihaploids. Euphytica, 69, 1-6.

CLULOW, S. A., WILKINSON, M. J., WAUGH, R., BAIRD, E., DE MAINE, M. J. AND POWELL, w. 1991. Cytological and molecular observations on Solanum phureja-induced dihaploid potatoes. Theor. Appl. Genet., 82, 545-551.

DE VRIES, S. E., FERWERDA, M. A., LOONEN, A. E. H. M., PIJNACKER, L. P. AND FEENSTRA, W. J. 1987. Chromosomes in somatic hybrids between Nicotiana plumbaginifolia and a monoploid potato. Theor. Appl. Genet., 75, 170-176.

DOYLE, J. J. AND DOYLE, J. L. 1987. A rapid DNA isolation procedure for small quantities of fresh leaf tissue. Phytochem. Bull., 19, 11-15.
GEBHARDT, C., MUGNIERY, D., RITTER, E., SALAMINI, F. AND BONNEL, E. 1993. Identification of RFLP markers closely linked to the $\mathrm{H} 1$ gene conferring resistance to Globodera rostochiensis in potato. Theor. Appl. Genet., 85, 541-544.

HAGBERG, S. G., LEHHMANN, L. AND HAGBERG, P. 1975. Segmental interchanges in barley. 1. Translocations involving chromosomes 5 and 6 . Hereditas, 80, 73-82.

HARDING, K. 1992. Detection of ribosomal RNA genes by chemiluminescence in Solanum tuberosum L: a rapid and nonradioactive technique for the characterisation of potato germplasm. Potato Res., 35, 199-204.

HAWkes, J. G. 1990. The Potato: Evolution, Biodiversity and Genetic Resources. Belhaven, London, pp. 208-209.

HEINER, R. E., KONZAK, C. F., NILAN, R. A. AND LEGAULT, R. R. 1960. Diverse ratios of mutations to chromosome aberrations in barley treated with diethyl sulphate and gamma rays. Proc. Natl. Acad. Sci. U.S.A., 46, 1215-1221.

HERMSEN, J. G. Th. AND VERDENIUS, J. 1973. Selection from Solanum tuberosum Group Phureja of genotypes combining high-frequency haploid induction with homozygosity for embryo spot. Euphytica, 22, 244-259.

KENTON, A., PAROKONNY, A. S., GLEBA, Y. Y. AND BENNETT, M. D. 1993. Characterization of the Nicotiana tabacum L. genome by molecular cytogenetics. Mol. Gen. Genet., 240, 159-169.

LAL, J. AND SRINIVASACHAR, D. 1979. Induction of segmental interchanges in pearl millet (Pennisetum typhides). Theor. Appl. Genet., 54, 27-32.

MARKS, G. E. 1955. A polyhaploid plant of Solanum polytrichon Rydb. Nature, 175, 469.

MEINKOTH, J. AND WAHL, G. 1984. Hybridization of nucleic acids immobilized on solid supports. Analyt. Biochem., 138, 267-284.

MONTELONGO-ESCOBEDO, H. AND ROWE, P. R. 1969. Haploid induction in potato: cytological basis for the pollinator effect. Euphytica, 18, 116-123.

MUKAI, Y., FRIEBE, B., HATCHETT, J. H., YAMAMOTO, M. AND GILL, B. S 1993. Molecular cytogenetic analysis of radiation-induced wheat-rye terminal and intercalary chromosomal translocations and the detection of rye chromatin specifying resistance to Hessian fly. Chromosoma, 102, 88-95.

OOMS, G., KARP, A., BURRELL, M. M., TWELL, D. AND ROBERTS, J. 1985. Genetic modification of potato development using Ri T-DNA. Theor. Appl. Genet., 70, 440-446.

PAROKONNY, A. S., KENTON, A. Y., GLEBA, Y. Y. AND BENNETT, M. D. 1992. Genetic reorganisation in Nicotiana asymmetrical somatic hybrids analysed by in situ hybridization. Plant J., 2, 863-874.

PELOQUIN, S. J., WERNER, J. E. AND YERK, G. L. 1990. The use of potato dihaploids in genetics and breeding. In: Tsuchiya, T. and Gupta, P. K. (eds) Chromosome Engineering in Plants: Genetics, Breeding, Evolution, Part B, pp. 79-92. Elsevier, Amsterdam.

PIJNACKER, L. P., FERWERDA, M. A., PUITE, K. J. AND ROEST, S. 1987. Elimination of Solanum phureja nucleolar chromosomes in $S$. tuberosum $+S$. phureja somatic hybrids. Theor. Appl. Genet., 73, 878-882.

Ross, H. 1986. Potato Breeding - Problems and Perspectives. Verlag Paul Parey, Berlin \& Hamburg. 
ROWE, P. R. 1974. Parthenogenesis following interspecific hybridization. In: Kasha, K. J. (ed.) Haploids in Higher Plants: Advances and Potential, pp. 43-53. University of Guelph, Guelph.

SAMBROOK, J., FRITSCH, E. F. AND MANIATIS, T. 1989. Molecular Cloning: a Laboratory Manual, 2nd edn. Cold Spring Harbor Laboratory Press, Cold Spring Harbor, New York. SOSA-CHAVEZ, R. AND HERNANDEZ DE SOSA, M. 1971. Use of dihaploids in the breeding of Solanum tuberosum L. 1 . Cytological considerations. Hereditas, 69, 83-100.

WAGENVOORT, M. 1988. Spontaneous structural rearrangements in Solanum tuberosum ssp. phureja: 1. Chromosome identification at pachytene stage. Euphytica, Suppl., 159-167.

WAUGH, R., BAIRD, E. AND POWELL, w. 1992. The use of RAPD markers for the detection of gene introgression in potato. Pl. Cell Rep., 11, 466-469.
WENZEL, G., SCHIEDER, O., PRZEWOZNY, T., SOPORY, B. K. AND MELCHERS, G. 1979. Comparison of single cell culture derived Solanum tuberosum L. plants and a model for their application in breeding. Theor. Appl. Genet., 55, 49-55.

WHITE, J. AND REES, H. 1985. The chromosome cytology of a somatic hybrid petunia. Heredity, 55, 53-59.

wILliams, C. E., HUNT, G. J. AND HELGESON, J. P. 1990. Fertile somatic hybrids of Solanum species: RFLP analysis of a hybrid and its sexual progeny from crosses with potato. Theor. Appl. Genet., 80, 545-551.

VISSER, R. G. F., HESSELING-MEINDERS, A., JACOBSEN, E., NIUDAM, H., WITHOLT, B. AND FEENSTRA, W. J. 1989. Expression and inheritance of inserted markers in binary vector carrying Agrobacterium rhizogenes-transformed potato (Solanum tuberosum L.). Theor. Appl. Genet., 78, 705-714. 